\title{
Setting the Stage for Collaborative Creative Leadership at Cirque du Soleil
}

\section{Laurent Simon}

\author{
"( A good juggler improving his skills, will juggle with more") \\ balls. An excellent juggler will juggle with balls of many \\ different sizes and shapes.
}

\author{
Boris Verkhovsky \\ Director of Acrobatics and Coaching, Cirque du Soleil
}

\begin{abstract}
Debates about the nature of leadership for creativity have been ongoing since the 1950s. But, despite the central role leadership plays in the management of creative processes, few contributions highlight the actual practice of leadership for collaborative creative ventures. This interview with the Director of Acrobatics and Coaching at Cirque du Soleil addresses the reflexive experience of a creative leader faced with the challenges of integrating multiple expertises around complex, technological, human, and poly-sensorial creative performances. In this context, leadership for collaborative creativity appears as a constant and dynamic balancing act between people, ideas, deliverables, and the position and personality of the leader.
\end{abstract}

\section{Introduction}

Cirque du Soleil, the Canadian live entertainment powerhouse, represents an extreme case of the strategic capability to exploit creativity. Founded 30 years ago in the Province of Québec, Canada, Cirque started as a street show in 1984 . Through a memorable series of shows in the nineties, which literally acted as a manifesto - with, for instance, "Le cirque réinventé" (We Reinvent the Circus) - Cirque du Soleil disrupted and reinvented the circus arts. It has been tremendously successful, and widely followed and imitated. Cirque ended up as multidimensional international creative business with 8 shows in Las Vegas, and 10 shows on tour all over the planet, and many developing franchises in media, cruises, resorts, and even restaurants. Renowned as a unique success in the entertainment industry, with a brand amongst the most admired and respected, Cirque du Soleil has always been strongly focused on the expression and demonstration of exceptional, individual and collective human physical performance. For the last 20 years, Boris Verkhovsky, Director of Acrobatics and Coaching at Cirque, and former coach of elite athletes in sport acrobatics in Russia and Canada, contributed to the cre- ation and development of most original physical performance acts at Cirque.

The interview with Boris Verkhovsky that forms the basis of this article was "performed" at Cirque du Soleil headquarters in Montréal, Canada on May 15, 2015. For the last 20 years, Cirque du Soleil has been described in research as a multi-dimensional creative powerhouse. It has been epitomized as an example of the so-called blue ocean strategy of business model disruption for new market creation in Kim and Mauborgne (2005). Its specific creative culture has been described and analyzed from the inside as inspired by strong leadership, enlightened story-telling, and collective engagement in creative endeavours (Baghai \& Quigley, 2011; Ghazzawi et al., 2014; Heward \& Bacon, 2006; Mahy, 2008a, 2008b; Saldaña Rosas, 2009). Cirque also appears in several research papers discussing strategic partnerships (Casadesus-Masanell \& Aucoin, 2009), creative processes (Aaker \& Joyce, 2013; Martin, 2009;), human resources and talent management (Massé \& Paris, 2013; Petiot, 2014), as well as its role in urban development and the creative city (Cohendet et al., 2010). Still, the repeated success of Cirque du Soleil retains an element of mystery, and it 


\section{Setting the Stage for Collaborative Creative Leadership at Cirque du Soleil}

\section{Laurent Simon}

remains challenging to grasp where its differentiation comes from. In this article, we attempt to lift a corner of the veil by discussing the role of leadership at the level of new project development and by analyzing its implementation in day-to-day practice between one experienced manager and the employees and creators involved in creative endeavours.

\section{Interview and Commentary}

In the realm of Cirque du Soleil, a show is made of a succession of acts contributing to the unfolding of a storyline inviting the audience into a unique and inspiring imaginary world. Viewed from the inside, an act is composed of a physical performance, performed by athlete-acrobats, a material setting with sometimes highly sophisticated technical devices, and choreography that instills aesthetic power and beauty to the movements of the performers. Original costumes and decors, along with live music and chant complete the poly-sensorial dimensions of the experience and contribute to its uniqueness.

With music, singing, and dancing, circus arts are likely to be among the oldest performing arts in human history. Representations of the staging of physical performance for entertainment purpose, often enhanced by technical apparatus, can be traced back to 5000 B.C. China, Egypt, Ancient Greece, and the Roman Empire. In one form or another, circus arts extended in history all over the world and throughout all cultures. Innovating in this field, with such strong traditions, appears as a major challenge.

Designing a novel, entertaining, unique acrobatic performance means engaging in a complex process, mobilizing varied expertise, deep and diverse experiences, trials and errors, learning in action, and reflexivity. It has to be a collective and collaborative process, and it requires the implementation of sophisticated leadership practices.

Throughout its history, Cirque has proven to be very efficient in attracting the best talent and expertise in the relevant fields of circus arts, but also "mise en scène", stage design, decor, composition, lighting, and the like. This attraction fed a pipeline of almost 30 years of continuously disruptive creativity, innovation, and success. However, such success is not achieved without overcoming challenges, many of which originate from the outside of the organization. "When high expertise mixes with repeated success, the risk is to be some- times too self-focused", states Boris. "At some point, you start to believe that you are the principal, if not unique initiator of creative ideas in your field."

Creative processes at Cirque are essentially formatted as an idea funnel, starting from an artistic vision and the intention to bring forth creative story-telling. Led by a creative director, this first intention has to be translated into a sequence of acrobatic acts, staging sometimes extreme physical performances, which are enhanced by dynamic choreographies, costumes, makeup, music, and chant. The process is complex, mixing a wide array of expert views, experiences, and aesthetic sensibilities. The outputs are largely uncertain and require constant translation from one field of knowledge to another, multiple interactions, and sophisticated debates. In this process, creation is by essence co-creation and requires a lot of maturity in terms of leadership and management practice.

"For thirty years, with repeated successes, we have been in the business of "wow!" That's a very important reality of what we do, and it impacts management. Because there are so many elements, each one should be at the level of 'wow', but the magic is when they collectively become 'wow'! In this regards, collaboration - and openness - is not an option. (...). When you come to the table for creation, an idea that's worthy, perhaps not in its full form, but as an initiator, a stepping stone in the creative process, can come from anybody. It can come from a costume designer, and yet it can transform into a performance opportunity. It can come from a composer or a 'metteur en scène'. We learned to respect it, to appreciate, and to be open enough to it."

Ideas are subtle artefacts, originating from half-conscious insights, fed by intuition, embedded previous experience, context sensitivity, and interpretation. Viewed as unfolding cognitive processes, ideas are at first vulnerable. They need to be acknowledged, nurtured, enriched, explained, translated, and equipped with a codebook, before being validated and legitimated. Respecting ideas, wherever they come from, and their progressive consolidation appears as a complex collective process to be led with extreme caution and subtle diplomacy.

"First of all, I think it comes from accepting people for who they are, and that means accepting mistakes. Our story taught us humbleness. Humbleness came with volumes of experience and repetition of the mandates, and realizing that you don't have a secret re- 


\section{Setting the Stage for Collaborative Creative Leadership at Cirque du Soleil}

\section{Laurent Simon}

cipe for creation. You realize at some point in time that if you're to compete against the world, you're going to lose. But we work with very intelligent people..."

Yet, even smart people need guidance, validation, approval, and reinforcement. The team leader acts consistently as a sense-maker, stating, wording, and revealing the essence and focus of the moment of collective action.

"If we live a collaborative moment, I would verbalize it: You were brilliant, taking that idea and bringing it to this achievement... If you capitalize on an example right away, you build an atmosphere where collaborative learning is possible. I deal with highly intelligent people and intelligence could lean towards arrogance sometimes... They're good at what they are and they got there in part because they're assertive, self-confident, and sometimes arrogant. If you go directly against someone, then you're in a fight. If you finger-point too directly at mistakes, you're antagonizing your counterpart. In the world of elite sports, the coach is always right; the performer is always wrong when there is a mistake. That is a horrible attitude. In that sense, I tried to make a difference, as a coach, by sharing in mistakes - that is humility. And I use that background and that experience in the way I work with the team."

In creative developments, mistakes and failures are part of the process. Harnessing a "failing forward" culture asks for a constant "maintenance" of genuine and open communication in the team. It has to be managed by example, based on empathy, respect, and self-awareness.

"I try to bring humbleness in our people when somebody criticizes a concept, of a costume, for instance. I will accept it. I will go into it. But I will shift gradually to the point of 'does it really impact us in a negative way or is it just a personal opinion?' And, when it comes to personal opinion how different is it from that of a professional. (...). Am I really in a position to offer expert opinion on costumes, or music, or makeup? It is a mix of entitlement and expertise... so humbleness is remembering how you would react and feel when somebody criticizes your work, without the basic understanding of it. This gives results, brings more collaboration, for sure. Because, then I will ask candid questions, use an opportunity to learn from you and to influence you, rather than simply pose the judgement on what you do."

The way the leader plays their role when faced with failure appears defining in fostering collective learning and reinforcing a generative dialog between team members.
"If I bring the focus on a failure, I always use myself as a part of the equation. And what I try to do - and I've been criticized for this - I very intentionally avoid the words "my team, my department...". I use the words 'our team, our department'... but when it comes to the error, I would definitely use 'I', like in 'I'm part of the problem, I didn't seen it coming. I failed to deliver on my membership in that team.' (...) That full notion of membership in a team, we put a fair amount of effort into discussing that. As a manager, I'm not with you on the floor, but I'm a member of your team. I have a role to contribute to the project as a member of the team, but just like in hockey, the goalie doesn't chase the puck. That's not his role. You expect him to focus on his role, and yet he is a member of the team, and a critical one! As the manager of my team, most of my role is focused on setting up the conditions for collaboration, in order to collectively generate, evaluate, enrich, and validate ideas."

The collective dynamics are constantly challenged, and there is a risk of irreconcilable divergence. Collaboration must be managed as the essential background of the creative process.

"What could foster collaboration? I have to be very cautious in answering, in order not to oversimplify it, but I would say 'Time'. Time together. For instance, when you say you spend 'quality time' with your kids, it's a fantastic excuse for not being available. No! Quality time implies time in duration. Because, when you schedule the time, it becomes nothing but efficiency, but when you deal with creativity, and when you deal with a human relationship there is melting and molding, and that takes time, and it's very difficult to schedule. I understand that in engineering and technological innovation you schedule the rhythm of activity, because you force it! In our area, it doesn't work like that."

But, the schedule still exerts pressure, and deliverables are expected on time. Reconciling the hierarchical demands and administrative constraints with these "open time sanctuaries" appears as a constant trade-off.

"The best way that it can work for me, is that I have really played on both sides of the fence, managing projects from the inside, and applying pressure on projects as an external manager. I have said 'no!' so many times to requests for extra time, and I have explained why. That gave me a lot more credibility later when I came and said 'I need more time'. We just delivered a project. We did it in a horribly compressed period of time, but we did it quite well. And we were ready to cel- 


\section{Setting the Stage for Collaborative Creative Leadership at Cirque du Soleil}

\section{Laurent Simon}

ebrate and I said to anybody: 'don't' rush to celebrate. Let's just wait. We just delivered.' And... here comes the critics! 'Well, you know, acrobatically I wished it would be a bit more.' When we delivered I knew the critics would come... and my answer was: when you remove all the time to breathe, and you pack the remaining time with so many tasks, there's zero room for development. As a matter of fact, we're so lucky that we were able to sustain the level we delivered. That realization, that assessment of what it takes to generate genuine creative content is not common in most companies, because you can't measure it. As a result, it is always easier to lean more on logistics and finances as the means of determining the time needed, but it is actually very risky when you're expecting the 'wow!' on every factor including the feeling of the story, the feeling of the experience, and smooth travel transitions throughout the show..."

In order to answer to pressure at the level of excellence that is expected by the public, management, the artists, and developers themselves, Boris Verkhovsky insists on the importance of collective engagement and solidarity in the project team as well as on stage.

"In our case, we play on the 'major' and the 'minor'. In the major, you're under the spotlight, performing at the front of the stage, very visible. In the minor, you're in the back, on the side, somehow in the shadows. I used to do things like filming an acrobat when he's in the minor. I film him in a close-up and show them afterwards. It's terrible, because they're thinking they're in a shady part of the stage. Yes, but still, probably 200 people are still looking at you at his very moment, so... picking your nose or not paying attention is really not an option! In the truthfulness of that, when you're in the minor, you're still on stage. It is the same during the development phases with the project team. The difficulty of major and minor and shifting from and to is definitely complicated with the group of people that we work with, in part because of personalities. In artistic and creative milieu, some people are so dynamic in their personality that their mode of operation is 'loud'. It's not a relay switch they can ramp up part-time. It's on or off. It's really tough, because partnership and co-work, co-ideation, co-creation is more about dialog. It's really tough on other people because the loud ones don't listen. That factor is a tough one for me, because it leans heavily on personality. What can I do with personalities? It has to go through dialog, time, and respect. I wouldn't impose a decision, sometimes even if the team was asking me to. I negotiate: 'You be who you are, but this is where I am in the process. Can you please, in the next session, help me in my quest?
After that, you be how you want to be.' Sometimes I play that game."

If team diversity is clearly an asset in terms of creative potential and enriching ideas with multiple perspectives and worldviews, it is also a major challenge for managers, who have to acknowledge unique personalities at every moment of the collaborative process.

"With the team, whenever you deal with more than two individuals, the sophistication of their thought and their background and philosophy make it a complex process. They're so different. It's normal. They're humans. I don't think you can have a formal model. One size doesn't fit all! It's not possible. (...). When you're coming out of elite coaching, effectively a very, very good coach has their methodology, and the students adjust. A master coach, will adjust the methodology. I think, in managing, when you're getting better at what you do, when you're really close to mastering that, you give yourself the freedom of adjusting the methodology with which you operate."

Adapting to individual personalities is a challenge, but managers must also consider background, expertise, experience, and legitimacy. Finding the right relative position requires a constant balancing act.

"I'm managing two teams of professionals as operational and functional supervisor, and a third one comes in just for creation: the choreography designers. With one group, I have a completely different professional package because I'm one of them. With the performance designers, I'm one of them. With equipment designers, I'm not at all. With choreography designers, I'm not. I understand it, but I'm not a choreographer, nor an equipment designer. And that's a tough challenge, because I have to use a completely different approach. There are times I'm questioning if my management of the group where I'm an expert is relevant because I'm too cautious to be too different from the others. The bases for interaction in one case are established on sharing the expertise, and in another case, not at all! With equipment and choreography, I have experience in managing them, but not experience in actually doing and fully, deeply understanding what they do. So from that perspective, it's a challenge - a major challenge. I think, in the method of their interactive contribution with the others, I would be asking them to be more cautious and smarter in what information they give me; to what degree of the detail they need to go into. Because, I can easily get overwhelmed with details in a field I'm not an expert in." 


\section{Setting the Stage for Collaborative Creative Leadership at Cirque du Soleil}

\section{Laurent Simon}

Setting the stage for collaboration means switching the focus between the individuals and the progress of the deliverables. Here, the manager aims at gathering pieces of knowledge and integrating them in the wider perspective of the project.

"In any interaction, as a manager, I would specify and re-specify what I need to know, and be very focused about it. I have to be crystal clear if I'm interested in the deliverable, in the schedule, or in some more specific details. Or I would say: on a scale of one hundred percent, do you feel that you've achieved this percent or that percent? Or I need only a bird's eye view, because I only need this or that... I would fluctuate from very concise, very pointed meetings, taking very few, very short notes, to give the notion of formality. I need those. Individuals need that. But then I would move away from it and we would go to a completely different format of a comfortable chair, a cup of coffee, and talk. It's a very critical need to fluctuate, between that format, and the setting, because it will give you very critical indications. You will be learning a lot more, and be able to influence a lot more. You restrict yourself to what is at stake there... I need to insist on the moments of formal validation, and the guys are going to feel constrained to it, but the guys would never miss a session of talk. I need to balance both."

Beyond the continuous adjustment of individuals' involvement and collective dialog on expertise, the most demanding challenge is to extend collaboration to the validation of progress made and deliverables.

"First, I would trust my own judgement, and manage the degree of my exposure. I learned that from theatre managers. I'm allowing myself to not watch the show every night, because then I will not really see it. I need to keep the freshness in order to see. But then, I would supplement it by the notion of peer review. What I would do is, if I feel that I'm over exposed to the project, at the risk of not seeing things anymore, because the eye gets used to it and accept it as a norm, then my critical judgment is perhaps reduced. Then I would not call a big event. Because events are disruptive to the process. They're imposing. So I will protect the process over that event, but I would bring in somebody, an experienced manager, a senior head coach, in order for me to see through their eyes... and we would talk through it."

In order to communicate and follow up with top management, the process needs to be formatted through a classical staging and gating approach. In this generic format, the leader uses gates as opportunities to focus on specific needs to be answered, and precise features to be evaluated and validated.

"I would use that notion of the gates and of course, every so often, I would formalize the gate. But, every time that we formalize the gate, if I have an opportunity, I manipulate what is my objective. It's not always the same. Sometimes it would be: it's an event, for the benefit of my boss. Sometimes that's what it is. And it's ok, if he's getting edgy, nervous, and in need to feel the project more. That's the objective, and I would be very clear. I would tell the guys, don't overdo it, it's not about you, it's for him, because when he speaks about the project, at top management or marketing level, he needs to have that kind of understanding. Sometimes I will prepare my partner who is going to do the peer review and say: 'Hey, please don't be judgmental because, all I want is just to stress for the team that they should focus on the performance with the presence of a first audience.' I use those extreme examples, but there are many in between. Those gates, they are quite specific and there is a range of objectives in them."

In terms of collaboration, a major, well-acknowledged risk is for the process to take over the content. The manager insist on fostering individual and collective reflexivity at the gate.

"You stage the gate with people above you, people that are parallel to you, and people that are below you. You need to do that. If you don't, it becomes pretentious, it causes frustrations, misunderstandings. We had to learn. So when I bring my VP, if I don't discuss with him well enough how I want it to go and what I'm expecting out of this gate, I'm at huge risk, because he would then start expressing an opinion: 'Why wouldn't you do that? Let's do that!' I would want to say: I'm not even interested in that, that's not an option, because that's not where we are now... but do I turn around and say that to my boss, in front of the others? That's out of the question. That means I failed at preparing that moment, and the staging of that. If I don't tie it to my objective, either I don't have the right objective, or I'm a really bad manager."

The need to define objectives extends further from the manager, to everyone involved in the project. "Runthroughs" are used as gates. They act as specific opportunities to refocus on individual and collective objectives, and to put them to the test of performance. Approaching the date of the premiere, the manager would invite a test audience of experienced peers, and even sometimes family members of the performers. It 


\section{Setting the Stage for Collaborative Creative Leadership at Cirque du Soleil}

\section{Laurent Simon}

raises the level of awareness of the performers, and brings them back to the intention of each individual. But the actual audience remains the acid test, and the ultimate goal.

"From that standpoint to me, it's being self-critical, individually and collectively. The presence of the audience enhances self-awareness and reflexivity. Do they see what we're hoping they would see? We're learning from them, what they see, how they react, and from what that we didn't even see. That's why with the "runthroughs" audience, we try to be cautious and strategic, very focused. We focus on the technical performance and the objectives of the performers. The individual intention has to fit in the moment of the performance - the precision and unique beauty of a gesture, in harmony with music, the decor, and other performers. The intention is to fit in the show, to perform, and to flow. But with the actual audience, it has a bigger goal: the artistic intention. When I say artistic, that is realizing that we're entertainers. We finally gather on this ultimate goal, of entertaining and inspiring people. When it works - if it works - we all know it. That's the greatest reward. It brings us back together, comforts us, reinforces us, and energizes us. We need that, because collective creation is an extremely laborious process".

\section{Conclusion}

From a manager's point of view, the organization of collective creativity and its channelling into collaborative performance remains a constant challenge. The direct account of Boris Verkhovsky's experience in managing new venture development at Cirque du Soleil allows us to see "through the looking glass" and draw some significant learning about the actual practice of leadership for creative collaboration.

First, creativity is not the exclusive privilege of some unique, talented, and well-identified creator. Ideas can come from many different stakeholders in the creative endeavour. One of the key roles of the leader is then to favour the expression of creative ideas by setting up a context of openness and respect, but also to sponsor and conduct discussions and debates about the creative and performing value of ideas. While doing so, the leader is also looking for the mobilization of diverse types of expertise in the evaluation of idea, and in complementing the idea with specific operational expertise. This challenge requires a complex balance of humbleness and authority. Humbleness plays an important role in being able to express and share half-baked in- sights, to play with them collectively in order to consolidate them, make them evolve, or discard them. Managing humbleness also means focusing on the attitude of people, being a role model in terms of listening and respectfully challenging an idea without invalidating the person expressing it. This learning stance, and the promotion of it, allows a team to play with ideas collectively, sometimes failing, making mistakes, and then rebounding from them and progressing.

Second, in this collective dynamic, the experienced leader will aim at setting the right conditions for creative expression and debates, by protecting quality time, and also by valuing solidarity in the team. Debates are worthwhile only if they are focused on the collective endeavour and are based on individual demonstrated expertise and experience rather than mere personal opinions or managerial authority. In order to keep this dynamic, the leader will constantly assess and very carefully manage their own position: mobilizing authority only when legitimized by expertise and experience, candidly requesting explanation and clarification when not in a knowledgeable position, fostering debate, and looking for external advice in case of ambiguity.

Third, in the formal staging-and-gating process, the leader will often tone down their direct authority on the content of the project and look for the validation of some features with specific stakeholders. In order to do so, a fair amount of effort is dedicated to the "staging" of the formal and informal gates. This means setting up a context for the demonstration of a feature, its collective and open discussion by carefully casted experts with the performers, and a fair evaluation of its value for the show. This practice aims at constantly enhancing self and collective awareness and reflexivity, and regularly reasserting the collective purpose: the entertainment of the audience, in this case.

Boris Vekhovsky's account of his experience at Cirque du Soleil in managing creative collaborative endeavours is consistent with the literature on creative contexts: it is based a strong and clear vision and purpose, on the integration of a diversity of expertise and experience, collective learning through trials and errors, and a playful and respectful team culture (Amabile, 1998). It also resonates with advanced leadership practice in creative project management, as fed by sense-making and purpose, connecting people for knowledge sharing and learning, defining and setting up the right playground in terms of freedom as well as constraints, and coaching the individuals and the team in their search for a 


\section{Setting the Stage for Collaborative Creative Leadership at Cirque du Soleil}

\section{Laurent Simon}

common flow (Csikszentmihalyi, 1997; Simon, 2006). Finally, addressing one of the major issues for contemporary organizations - the transformation of a diversified collective of creative people into a performing creative collective (Hargadon \& Bechky, 2006) - it clarifies the expression of leadership for collaborative creativity in practice, as a constant position game, strategizing expertise, authority, and participation and accelerating the exploration and validation of new ideas by fostering individual and collective reflexivity.

\section{References}

Aaker, J., \& Joyce, S. 2013. Cirque du Soleil: Cultivating Creativity and Designing to Delight. Case No. M353. Stanford Business School.

Amabile, T. M. 1998. How to Kill Creativity. Harvard Business Review, 76(5): 76-87.

Baghai, M., \& Quigley, J. 2011. As One: Individual Action, Collective Power. New York: Penguin Group (USA).

Casadesus-Masanell, R., \& Aucoin, M. 2009. Cirque du Soleil: The High-Wire Act of Building Sustainable Partnerships. HBS Case No. 709-411. Harvard Business School Strategy Unit.

Cohendet, P., Grandadam, D., \& Simon, L. 2010. The Anatomy of the Creative City. Industry and Innovation, 17(1): 91-111. http://dx.doi.org/10.1080/13662710903573869

Csikszentmihalyi, M. 1997. Flow and the Psychology of Discovery and Invention. New York: HarperPerennial.

Ghazzawi, I. A., Martinelli-Lee, T., \& Palladini, M. 2014. Cirque du Soleil: An Innovative Culture of Entertainment. Proceedings of the International Academy for Case Studies, 21(5): 15-17.

Hargadon, A. B., \& Bechky, B. A. 2006. When Collections of Creatives Become Creative Collectives: A Field Study of Problem Solving at Work. Organization Science, 17(4): 484-500.

http://dx.doi.org/10.1287/orsc. 1060.0200

Heward, L., \& Bacon, J. U. 2006. Cirque du Soleil. The Spark: Igniting the Creative Fire That Lives Within Us All. New York: Random House.

\section{About the Author}

Laurent Simon is an Associate Professor in the Department of Entrepreneurship and Innovation at the HEC Montréal business school in Montreal, Canada, where he is also the Co-Director of Mosaic, the Creativity \& Innovation Hub. His current research focuses on characterizing the management of techno-creative projects and the study of creative environments and practices, the management of creative projects, creative communities, "creative cities", and the determinants of creativity in innovation management.

Kim, W. C., \& Mauborgne, R. 2005. Blue Ocean Strategy: How to Create Uncontested Market Space and Make the Competition Irrelevant. Boston: Harvard Business School Press.

Mahy, I. 2008. "Il était une fois... " Ou la force du récit dans la conduite du changement. Communication et Organisation, 33: $50-60$.

Mahy, I. 2008. Les coulisses de l'innovation. Création et gestion au Cirque du Soleil. Quebec City: Les Presses de l'Université Laval.

Martin, R. 2009. The Design of Business. Why Design Thinking Is the Next Competitive Advantage. Cambridge, MA: Harvard Business Press.

Massé, D., \& Paris, T. 2013. Former pour entretenir et développer la créativité de l'entreprise : les leçons du Cirque du Soleil. Gestion, 38(3): 6-15.

http://dx.doi.org/10.3917/riges.383.0006

Petiot, B. 2014. Le Cirque du Soleil : un outil de création et de production unique. Le journal de l' École de Paris du management, 105(1): 23-29.

http://dx.doi.org/10.3917/jepam.105.0023

Saldaña Rosas, A. 2009. Momentos de gracia : Organizar lo imposible. Biblioteca Veracruzana - Universidad Autonoma Metropolitana.

Simon, L. 2006. Managing Creative Projects: An Empirical Synthesis of Activities. International Journal of Project Management, 24(2): 116-126. http://dx.doi.org/10.1016/j.ijproman.2005.09.002 